\title{
COMUNICACIÓN
}

\section{VALOR NUTRITIVO DE CUATRO ESPECIES SILVESTRES DE CONSUMO HUMANO EN LA CIUDAD DE IQUITOS}

\author{
Nofre Sánchez P. ${ }^{1}$, Teresa Arbaiza F.2 y Orlando Lucas A.²
}

\section{Awiract}

The nutritional quality of white alligator (Caiman crocodilus crocodilus), taricaya (Podocnemis unifilis), carachupa (Dasypus novemcinctus) and churo (Pomacea maculata) meat was evaluated by chemical and mineral composition analysis. The animals were purchased at Belen market in Iquitos. The results by species are: white alligator: humidity $74.34 \%$, dry matter $25.67 \%$, protein $22.54 \%$, ether extract $0.85 \%$ and ash $1.07 \%$; taricaya: humidity $76.58 \%$, dry matter $23.43 \%$, protein $20.52 \%$, ether extract $0.62 \%$ and ash $1.13 \%$; carachupa: humidity $74.45 \%$, dry matter $25.55 \%$, protein $22.86 \%$, ether extract $0.56 \%$ and ash $1.24 \%$; churo: humidity $74.67 \%$, dry matter $25.33 \%$, protein $16.21 \%$, ether extract $0.56 \%$ and ash $1.83 \%$. Calcium and phosphorus content $(\mathrm{mg} / 100 \mathrm{~g})$ was: white alligator 3.411,179.61; taricaya 11.50, 173.05; carachupa 10.44, 196.26 and churo 636.85, 112.40. The net energy $(\mathrm{kcal} / 100 \mathrm{~g})$ was $103.74,102.65,91.45$ and 74.25 for white alligator, taricaya, carachupa and churo.

Key words: Mountain meat, nutritive value.

Palabras clave: Carne de monte, valor nutritivo.

Como consecuencia de la creciente demanda mundial de alimentos en general y especialmente de proteína de origen animal de alta calidad a un costo razonable, resulta cada vez más necesario recurrir a nuevas fuentes con posibilidades zootécnicas, económicas y de buena rentabilidad (Bendayán, 1991). En tal sentido, se está experimentando un gran impulso en la cría de animales tanto aquellos situados en los primeros eslabones de las

I Estación Experimental IVITA -Iquitos - FMV UNMSM. E.mail: dJ70060@unmsm.edu.pe 2 Laboratorio de Nutrición Animal IVITA - FMV - UNMSM. cadenas tróficas de los ecosistemas, como es el caso del caracol terrestre, por su capacidad transformadora de alimentos de baja calidad, costo y sus elementales necesidades nutritivas (Guerrero y Romero, 1995; Campoverde, 1992), así como otras especies de la fauna de selva baja. Por esta razón se planteó el presente estudio para conocer las cualidades nutritivas de las porciones comestibles del Lagarto blanco (Caiman crocodilus crocodilus) macho, porción cola; taricaya (Podocnemis unifilis) hembra, miembro posterior; carachupa (Dasypus novemcinctus) macho, miembro posterior; y churo (Pomacea maculata). 
Las muestras fueron compradas en los diferentes puestos de venta, considerando las preferencias del consumidor, las que fueron congeladas y enviadas a la ciudad de Lima. Se realizaron las siguientes determinaciones: Proteína, extracto etéreo, cenizas (Arbaiza, 1997), calcio y fósforo (AOAC, 1990), y se calculó el contenido de energía bruta y la porción comestible.

El lagarto blanco tuvo el mayor porcentaje de la porción comestible (Cuadro 1). En el lagarto y carachupa estas porciones son blancas y suaves al tacto. La taricaya, típica carne roja, tiene una consistencia suave y por último, el churo tiene una coloración oscura en el exterior y al corte es de color blanquecino.

La composición química (Cuadro 1) de las carnes de lagarto, carachupa y taricaya no muestran diferencias notorias entre ellas; sin embargo se observan claras diferencias con respecto al churo. Este último muestra un menor contenido proteínico y mayor contenido de calcio.

Se concluye que estos alimentos usados por la población tienen una alta calidad nutritiva, similar a las carnes de los animales domésticos.

Cuadro 1. Composición química bromatológica de las porciones comestibles de cuatro especies silvestres de consumo humano (en base seca).

\begin{tabular}{lcccccccc}
\hline Especie & $\begin{array}{c}\text { Hume- } \\
\text { dad, } \\
\%\end{array}$ & $\begin{array}{c}\text { Proteí- } \\
\text { na, } \\
\%\end{array}$ & $\begin{array}{c}\text { E. Eté- } \\
\text { reo, } \\
\%\end{array}$ & $\begin{array}{c}\text { Ceni- } \\
\text { zas, }\end{array}$ & $\begin{array}{c}\text { Calcio, } \\
\text { mg }\end{array}$ & $\begin{array}{c}\text { Fósforo, } \\
\text { mg }\end{array}$ & $\begin{array}{c}\text { Energía } \\
\text { bruta, } \\
\text { kcal }\end{array}$ & $\begin{array}{c}\text { Porción } \\
\text { comestible, } \\
\%\end{array}$ \\
\hline Lagarto & 74.34 & 22.54 & 0.85 & 1.07 & 3.41 & 179.61 & 103.74 & 63.3 \\
Taricaya & 76.58 & 20.52 & 0.62 & 1.13 & 11.50 & 173.05 & 91.45 & 55.2 \\
Carachupa & 74.45 & 22.86 & 0.56 & 1.24 & 10.44 & 196.16 & 102.65 & 49.4 \\
Churo & 74.67 & 16.21 & 0.56 & 1.83 & 636.85 & 112.40 & 74.25 & 51.0 \\
\hline
\end{tabular}

\section{Titeratura Cinda}

1. Arbaiza, T. 1997. Evaluación química del contenido de nutrientes de los elementos. Fac.Med.Vet. UNMSM. Lima, Perú.

2. AOAC. 1990. Official Methods of analysis. 15th. Ed. Association of Official Analytical Chemists. USA.

3. Bendayán, A. N. 1991. Influencia socioeconómica de la fauna silvestre como recurso alimentario. Tesis para optar el título. UNAP. Iquitos
4. Campoverde, R.L. 1992. Posibilidad de manejo del caracol terrestre Megalobulimus maximus, como recurso proteica en San Martín, Tesis para optar el título. UNALM. Lima. 83p.

5. Guerrero, R.L. y M.C. Romero. 1995. Estudio de factibilidad para la instalación de una granja de crianza y reproducción de caracoles de tierra (Helix aspersa) para su posterior procesamiento con fines de exportación a Francia. Tesis para optar el título. UNALM. Perú. 